\title{
A Test of the Potential Curvilinear Relationship Between Students with Middle-range Performance and Received Teachers' Attention
}

\author{
YUNUO YAO
}

\author{
Beijing Haidian Foreign Language Academy, Beijing 100093, China \\ 1973933692@qq.com
}

\begin{abstract}
Teenagers have infinity potential, especially in adolescence. At this time, teenagers are sensitively influenced by factors in their life, including schools. In high school daily life observation, students with high or low academic and extracurriculars performance received high attention from teachers. Students with average academic and extracurriculars performance receive less attention from teachers. Then those students may feel discomfort and lack of confidence. The author wants to appeal to the concern of the majority about the psychological needs of students with average academic and extracurriculars. In this paper, the author finds the curvilinear relationship between students' performance and teachers' attention they received by correlational study. And the graph is U shape.
\end{abstract}

Keywords: academic performance, teachers, attention

\section{INTRODUCTION}

Grading system has long history around the world; however, it is not always reliable. Some forms of assessment lend themselves to greater levels of grading subjectivity than others.[1] Grading student writing, whether in essays, reports, or constructed-response test items, opens up greater opportunities for subjectivity.[1] It is obvious that teachers play crucial role in students life. Moreover, in previous study, some researchers proposed that teachers pay more attention to the "better" students, and that these students in turn respond by talking more in the discussion.[2] The figure 1 below shows the specific data of that research.

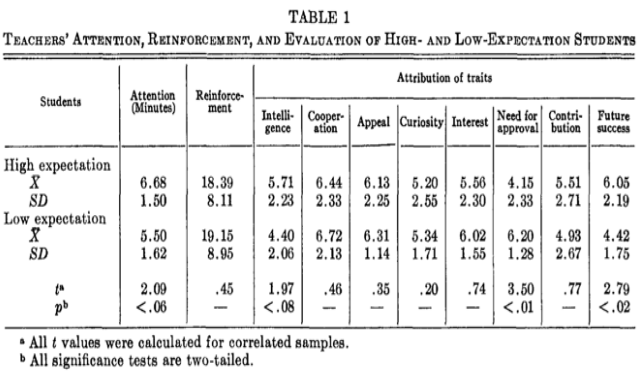

Figure 1 Specific data of EFFECTS OF TEACHER'S

EXPECTANCY ON STUDENT-TEACHER

INTERACTION research
In addition, in the learning environment, teacherstudent interaction plays a major role in influencing the cognitive and affective development of students due to their different thinking style which shown below in figure 2 and 3. [3]

\begin{tabular}{|c|c|c|c|c|c|c|c|}
\hline & \multicolumn{2}{|c|}{ Cronbach's alpha } & \multicolumn{2}{|c|}{ Student smple } & \multicolumn{2}{|c|}{ Tescher sample } & \multirow[b]{2}{*}{ Mean difference } \\
\hline & Sudent sample & Teachet sample & $\bar{M}$ & $S D$ & $\bar{M}$ & $S D$ & \\
\hline 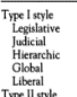 & $\begin{array}{l}.71 \\
.79 \\
.78 \\
.85\end{array}$ & $\begin{array}{l}.76 \\
.70 \\
.80 \\
.84 \\
.84\end{array}$ & $\begin{array}{l}5.20 \\
4.96 \\
4.93 \\
4.23 \\
4.62\end{array}$ & $\begin{array}{l}0.94 \\
1.01 \\
0.96 \\
0.93 \\
0.84\end{array}$ & $\begin{array}{l}5.05 \\
4.50 \\
5.11 \\
4.20 \\
4.52\end{array}$ & $\begin{array}{l}0.79 \\
0.70 \\
0.80 \\
0.65 \\
0.75\end{array}$ & $\begin{array}{c}0.15^{\circ . *} \\
0.46 \cdot \\
-0.10^{\circ} \\
\text { n. } \\
0.10^{\circ}\end{array}$ \\
\hline 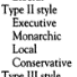 & $\begin{array}{l}.70 \\
.69 \\
.61 \\
.71\end{array}$ & 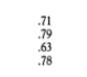 & $\begin{array}{l}3.17 \\
4.56 \\
4.45 \\
4.55\end{array}$ & $\begin{array}{l}0.80 \\
1.03 \\
0.97 \\
1.02\end{array}$ & $\begin{array}{l}5.17 \\
4.66 \\
4.31 \\
4.66\end{array}$ & $\begin{array}{l}0.73 \\
0.70 \\
0.78 \\
0.86\end{array}$ & $\begin{array}{l}-2.000 \\
-0.100^{\circ} \\
0.14 \\
-0.11\end{array}$ \\
\hline $\begin{array}{l}\text { Type Ill stryle } \\
\text { Oligarchic } \\
\text { Anarchic } \\
\text { Intemal } \\
\text { External }\end{array}$ & $\begin{array}{l}.78 \\
.78 \\
.78 \\
.79\end{array}$ & $\begin{array}{l}.75 \\
.72 \\
.79 \\
.76\end{array}$ & 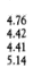 & $\begin{array}{l}0.98 \\
0.92 \\
0.99 \\
0.95\end{array}$ & $\begin{array}{l}3.44 .45 \\
3.10 \\
5.101\end{array}$ & $\begin{array}{l}0.81 \\
0.83 \\
0.85 \\
0.90\end{array}$ & 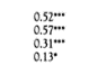 \\
\hline
\end{tabular}

Figure 2 Characteristics of Thinking Styles of Teachers and Students. 


\begin{tabular}{|c|c|c|c|c|c|c|c|}
\hline & \multicolumn{2}{|c|}{ Crontach's alpha } & \multicolumn{2}{|c|}{ Student sample } & \multicolumn{2}{|c|}{ Teacher sample } & \multirow[b]{2}{*}{ Mean difference } \\
\hline & Student sample & Teacher sample & $\bar{M}$ & $\overline{S D}$ & $\bar{M}$ & $\overline{S D}$ & \\
\hline 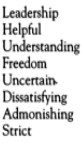 & $\begin{array}{l}.72 \\
.83 \\
.79 \\
.81 \\
.81 \\
.68 \\
.58\end{array}$ & $\begin{array}{l}.69 \\
.70 \\
.65 \\
.68 \\
.70 \\
.61 \\
.66\end{array}$ & $\begin{array}{l}5.25 \\
5.67 \\
5.75 \\
4.48 \\
1.89 \\
1.85 \\
1.99 \\
3.69\end{array}$ & $\begin{array}{l}1.04 \\
0.93 \\
0.81 \\
0.88 \\
0.08 \\
0.90 \\
0.76 \\
0.87\end{array}$ & $\begin{array}{l}5.47 \\
5.58 \\
5.74 \\
4.45 \\
2.49 \\
2.87 \\
2.33 \\
4.02\end{array}$ & $\begin{array}{l}0.68 \\
0.65 \\
0.58 \\
0.65 \\
0.80 \\
0.90 \\
0.05 \\
0.81\end{array}$ & $\begin{array}{c}-0.22 \cdot \\
n s \\
n s \\
n s \\
-0.60 . \cdots \\
-1.02 \cdots \\
-0.34 \cdots \\
-0.34 \cdots\end{array}$ \\
\hline
\end{tabular}

Figure 3 Teachers' and Students' preferred TeacherStudent Interpersonal Behavior.
Students for whom teachers held high performance expect tended to perceive more positive and less negative oral feedback than those whom teachers held low performance expectancies.[4] According to those facts from literature, to some extent, teachers' behaviors can affect students significantly. Some researchers thinks the SEL (Social and Emotional Learning) also affect students performance [5] The figure 4 below indicates three component framework for SEL.

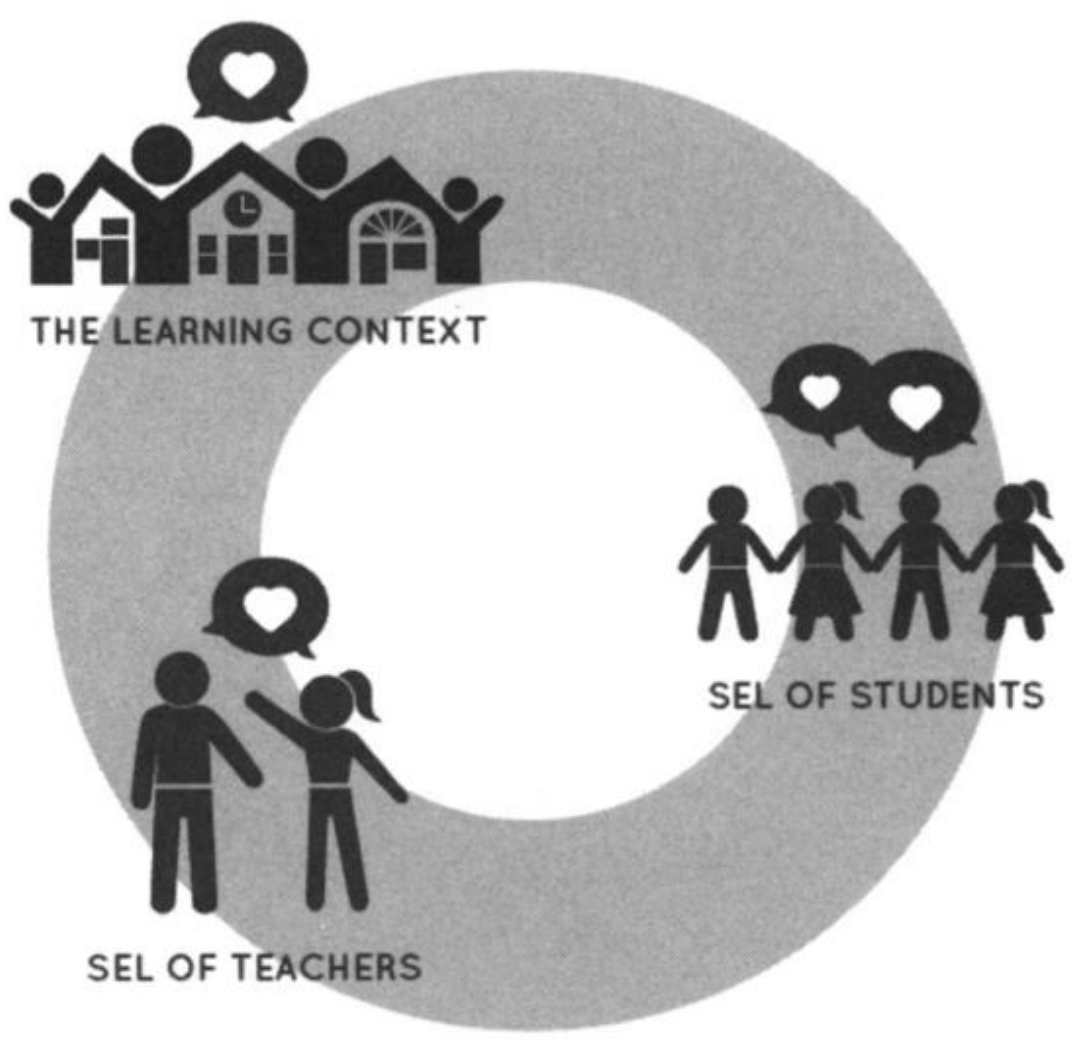

Figure 4 Three-Component Framework for SEL

Nevertheless, there is nearly no papers which write the topic which can directly indicates the influence teachers on students: students' academic performance and teachers' attention they received.

Such is human nature to be attracted by some outstanding behaviors no matter that superior or inferior to others. Some teachers' behaviors can be explained by this truth, too. In the majority of high schools in China, students who have average academic performance and extra curriculum performance are neglected and lacked attention from their teachers. Some students said they felt hurts and even were trapped in self-deny because of a long time lacking praise from teachers. If this situation lasts for a long time, there may be a serious consequence - students may give up chances to develop various skills due to lack of confidence, thus become people with no outstanding characteristics and be even more self-deny. Moreover, there are no relevant papers related to students with average performance receiving less attention from teachers, so doing research and prove there is a curvilinear relationship. After proving, teachers probably can adjust their behaviors and students can grow happily.

\section{METHOD}

Participants. 40 individuals participated. 10 participants were excluded because they did not give back the answers to the questionnaire.

\section{Questionnaire}

1. What are your average grades in the latest year?
A. $90-100$
B. $80-89$
C. $70-79$ 

D. $60-69$
E. Below 60

2. How much do you think the attention 【carness or comforting】 you receive from teachers in the latest year? (percentage)

1. 80-100

2. $60-79$

3. $40-59$

4. $20-39$

5. $0-19$

The operational definition is A equals 5, B equals 4, $\mathrm{C}$ equals 3, D equals 2, and E equals 1 . Students' grades are in the range of 90-100 are cataloged to students with higher academic performance. Students' grades are in the range of 60 and below 60 are cataloged to students with lower academic performance. The rest of the students are cataloged to students with average academic performance.

\subsection{Experimental design}

Procedures: Firstly, 40 participants were separated into different grades stages by using their grades reports. Secondly, surveys which are questionnaires was done to evaluate the teachers' attention receive by students. Even though students are asked to answer their grades in the latest year, researchers still use the grade report since the question asking about grade is the hint which direct students. Thirdly, answers from students and grades reports were analyzed by using the operational definition. Fourthly, because a number that represents the grade of a certain stage corresponds to several numbers representing the attention of the teacher to the students, the numbers representing the attention of the teacher to the students were analyzed again by finding their average numbers. Fifthly, the dot-plot was created as shown in Figure 5 and there was also a curvilinear relationship exist as shown in Figure 6. Finally, data were compared and find the difference.

Measure 1. Using students' final grades to find students with middle-range academic performance

Measure 2. Using self-reports questionnaire to find whether students receive high or low attention from teachers

\subsection{Result}

\section{attention receiving}

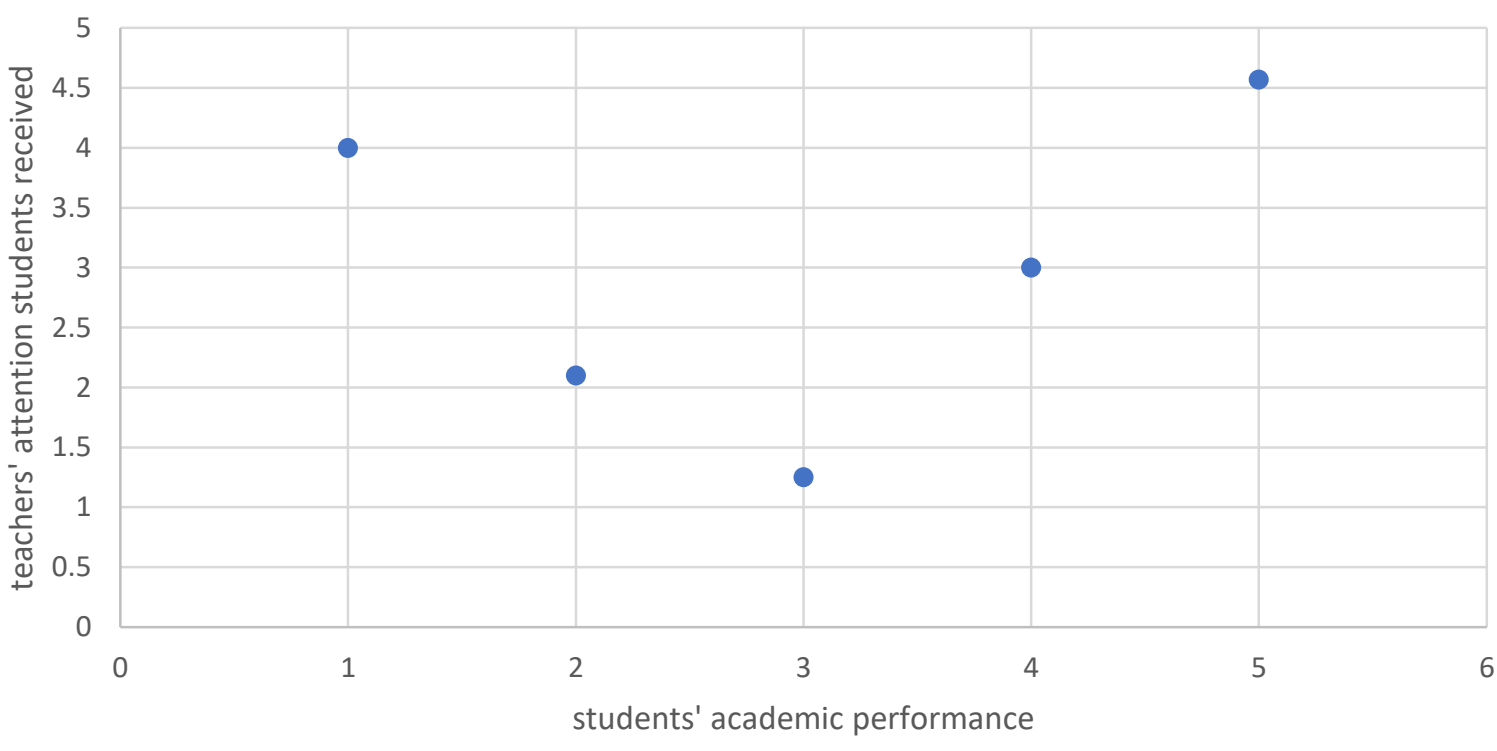

Figure 5 The dot-plot graph of the relationship of students' academic performance and teachers' attention they received 


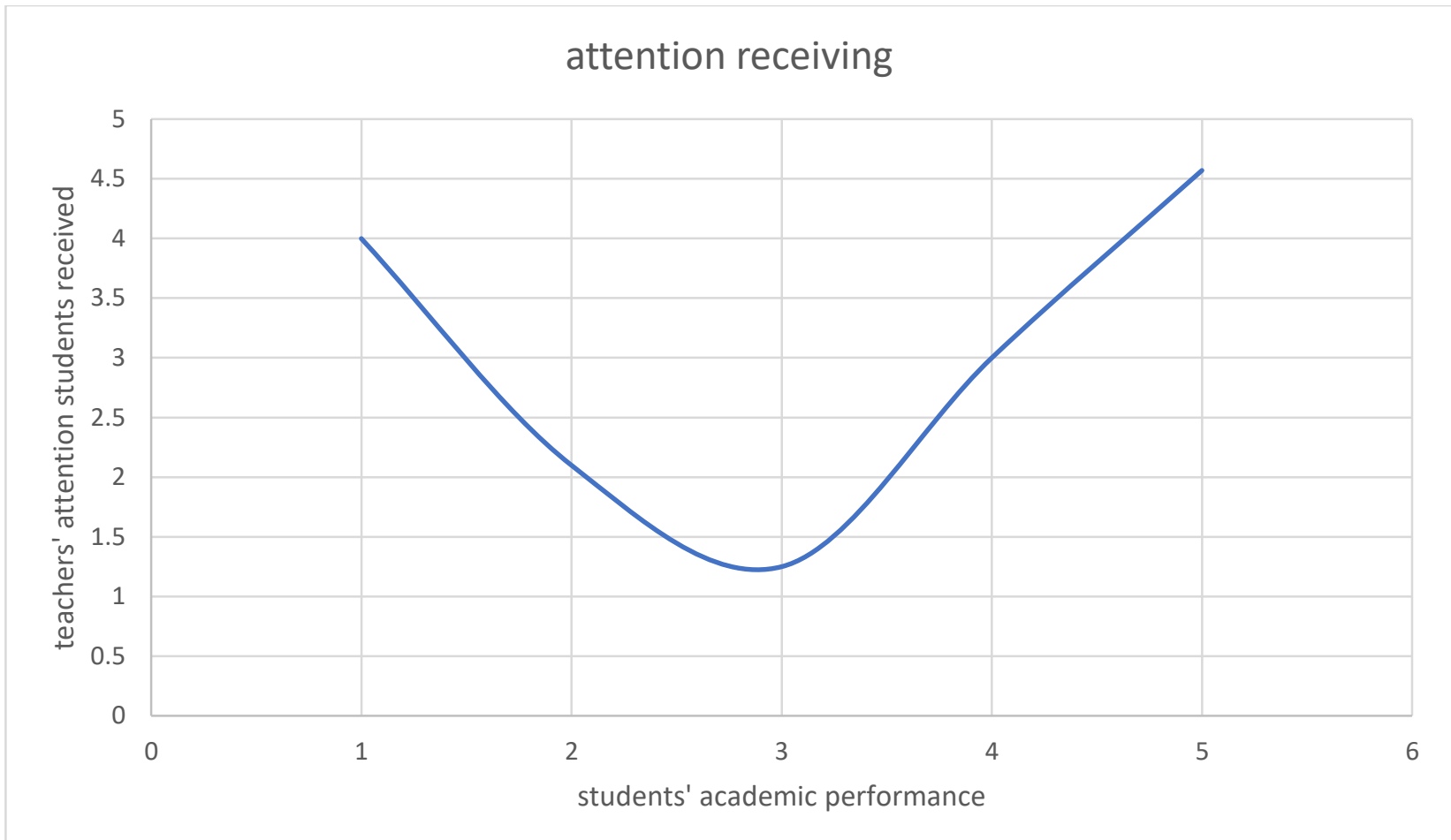

Figure 6 the curvilinear graph of the relationship of students' academic performance and teachers' attention they received

\section{CONCLUSION}

From the graph, within the range of 30 participants, the attention received by students with lower and higher academic performance is 3.857 . However, the attention received by students with average academic performance is 1.675 . It is shown that the difference between the attention students received is huge. This result also indicates teachers tend to pay more attention to those students who have extreme performance may be due to their extreme performance is more eye-catching. However, Kimberly A. Schonert-Reichl thinks the healthy and safe learning environment should be correspond with The Prosocial Classroom Model which is shown below in figure 7 .

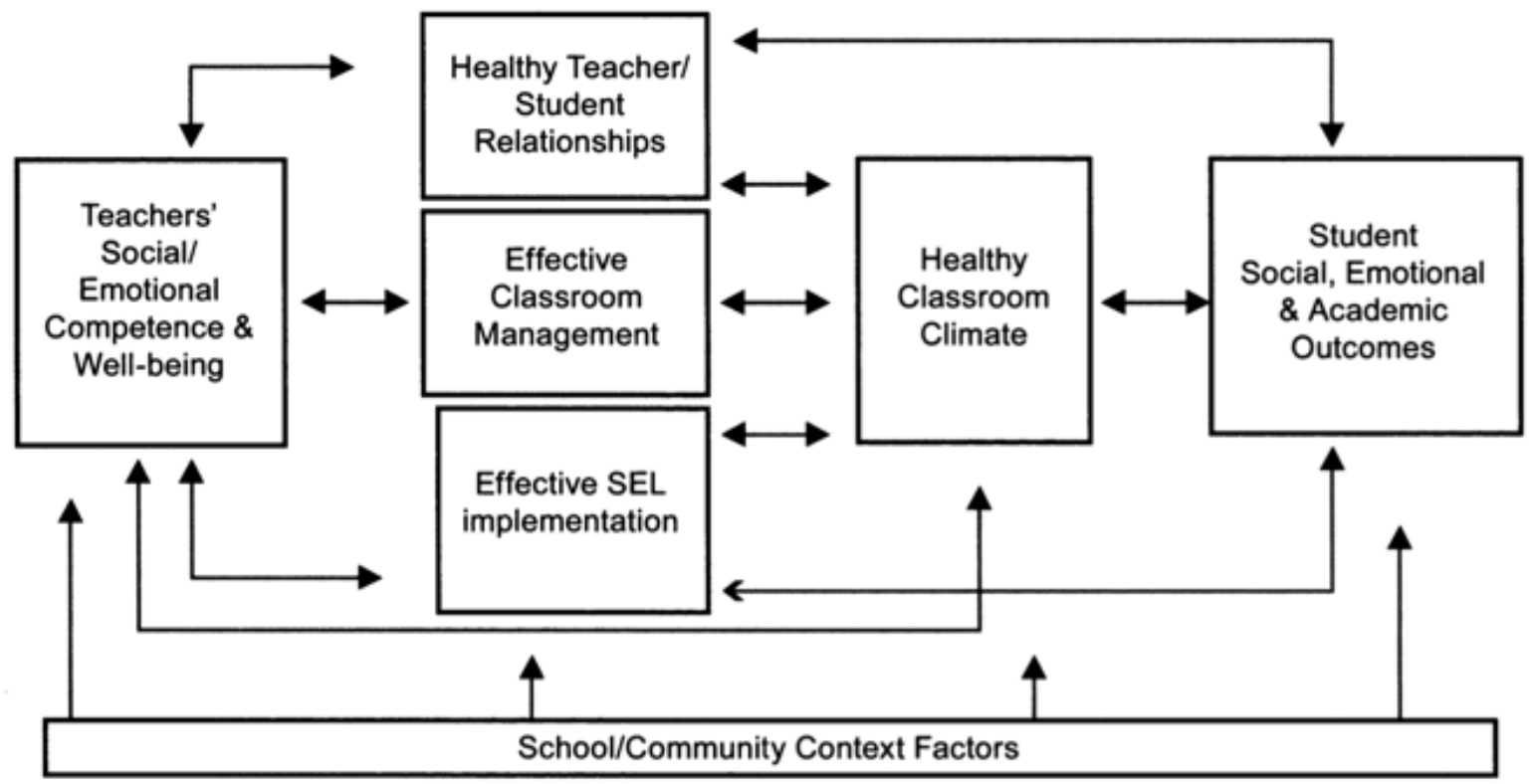

Figure 7 The Prosocial Classroom Model. 


\subsection{Reflection}

There are some mistakes in the research. It is better to find more participants in school as possible; however, since researcher did not find participants earlier, and lost the chance to find more individuals because it was hard to contact students who are on vacation. It was better to have students in different places to participate in so that the results tend to be more convincing like students from Beijing or even China. However, researcher did not have so much time to find those participants. When researcher first planed this research, she designed a wrong questionnaire which contained questions which could not collect useful data and could not analyze the data. Because of that, researcher had to redesign the questionnaire, which caused some participants were unwilling to join the research and the researcher had to ask other group of students. The mistakes on questionnaire wasted researcher much time and delayed the research program.Moreover, future research can find which personalities students with average academic performance have resulted in teachers neglecting and the result of teachers neglecting on students with an average academic performance by using valid self-report measures. At last, during the writing process, researcher did not plan my schedule, so it took researcher long time to finish.

\section{REFERENCES}

[1] Schinske, J., \& Tanner, K. (2017). Teaching More by Grading Less (or Differently). CBE-Life Sciences Education, 13, 159-166.

[2] Rothbart, M., Dalfen, S., \& Barrett, R. (1971). EFFECTS OF TEACHER'S EXPECTANCY ON STUDENT-TEACHER INTERACTION. Journal of Educational Psychology, 62, 49-54.

[3] Chuan, Z. (2013). Students and Teachers' Thinking Styles and Preferred Teacher Interpersonal Behavior. The Journal of Educational Research, 106, 399-407.

[4] Chen, Y., Thompson, M. S., Kromrey, J. D., \& Chang, G. H. (2011). Relations of Student Perceptions of Teacher Oral Feedback With Teacher Expectancies and Student Self-Concept. The Journal of Experimental Education, 79, 452-477.

[5] Schonert-reichl, K. A. (2017). Social and Emotional Learning and Teachers. THE FUTURE OF CHILDREN, 27(1), 137-155. 